\title{
DIFFERENCE OF VO2 MAX LEVEL BETWEEN FOOTBALL AND BASKETBALL PLAYERS
}

\author{
Muhammad Fajar Husein, Wijianto
}

Graduate Program of Physiotherapy, Universitas Muhammadiyah, Surakarta

\begin{abstract}
Background: Maximal oxygen uptake (VO2max) has been regarded by majority of authors as the best indicator of aerobic capacity of an organism, and at the same time, the best indicator of an athlete's physical capacity. The aim of the study was to compare physical capacity of athletes by measuring differences in VO2max capacity with regard to the kind of sport they are practicing.

Subjects and Method: A cross-sectional study was conducted at Universitas Muhammadiyah Surakarta, Central Java, Indonesia. A sample of 26 athletes consisting of 12 football players and 14 basketball players aged 20 to 29 years was selected for this stduy. The exlusion criteria were smoker and athletes with heart disease or pulmonary disease. The dependent variable was $\mathrm{VO}_{2}$ max. The independent variable was type of sport. Mean difference of $\mathrm{VO}_{2}$ max between groups was examined using Mann-Whitney. Results: $\mathrm{VO}_{2}$ max in football players (Mean= 42.96; $\mathrm{SD}=3.55$ ) was higher than basketball players (Mean $=39.65 ; \mathrm{SD}=4.88$ ) and it was statistically significant.

Conclusion : $\mathrm{VO}_{2}$ max in football players is higher than basketball players.
\end{abstract}

Keywords: $\mathrm{VO}_{2}$ max, football player, basketball player

\section{Correspondence:}

Muhammad Fajar Husein. Graduate Program of Physiotherapy, Universitas Muhammadiyah, Surakarta. Email: Gemilanggean@gmail.com. 